IZA DP No. 9083

Does Holding a Postdoctoral Position Bring Benefits for Advancing to Academia?

Eric S. Lin

Shih-Yung Chiu

May 2015 


\title{
Does Holding a Postdoctoral Position Bring Benefits for Advancing to Academia?
}

\author{
Eric S. Lin \\ National Tsing Hua University \\ and IZA \\ Shih-Yung Chiu \\ National Cheng Kung University
}

Discussion Paper No. 9083

May 2015

IZA

P.O. Box 7240

53072 Bonn

Germany

Phone: +49-228-3894-0

Fax: +49-228-3894-180

E-mail: iza@iza.org

Any opinions expressed here are those of the author(s) and not those of IZA. Research published in this series may include views on policy, but the institute itself takes no institutional policy positions. The IZA research network is committed to the IZA Guiding Principles of Research Integrity.

The Institute for the Study of Labor (IZA) in Bonn is a local and virtual international research center and a place of communication between science, politics and business. IZA is an independent nonprofit organization supported by Deutsche Post Foundation. The center is associated with the University of Bonn and offers a stimulating research environment through its international network, workshops and conferences, data service, project support, research visits and doctoral program. IZA engages in (i) original and internationally competitive research in all fields of labor economics, (ii) development of policy concepts, and (iii) dissemination of research results and concepts to the interested public.

IZA Discussion Papers often represent preliminary work and are circulated to encourage discussion. Citation of such a paper should account for its provisional character. A revised version may be available directly from the author. 


\section{ABSTRACT \\ Does Holding a Postdoctoral Position Bring Benefits for Advancing to Academia?*}

Postdoc is a special transitional position for those with a doctoral degree and is usually regarded as an investment to accumulate the additional human and social capital needed to facilitate future job searches or to add to an academic reserve army of unemployed PhDs. Given the prevalence of postdoctoral positions nowadays, it is crucial to explore the role played by postdoctoral participation in the post-PhD labor market. By taking advantage of a comprehensive data set from the National Profiles of Human Resources in Science and Technology in Taiwan, we first explore several characteristics associated with the choice of a postdoctoral position for newly-minted doctoral degree holders, such as age, discipline or the time taken to complete the degree. We then apply the control function approach to address the possible endogenous decision of postdoctoral experience when estimating the effects of postdoctoral positions on the current career choices between academic and non-academic jobs. The empirical results suggest that engaging in postdoctoral positions could increase the probability of advancing to the academic sector by about $6.1 \%$. The heterogeneous effects of gender, major and cohort in regard to the postdoctoral experience are also found by splitting the data. Moreover, we experiment with several groupings for the definition of being awarded an academic position and obtain very robust empirical results.

JEL Classification: $\quad$ 12, J24

Keywords: $\quad$ PhD, postdoctoral position, academia, job choice

Corresponding author:

Eric S. Lin

Department of Economics

National Tsing Hua University

Hsin-Chu 30013

Taiwan

E-mail: slin@mx.nthu.edu.tw

\footnotetext{
* We would like to thank the Science and Technology Policy Research and Information Center, National Applied Research Laboratories in Taiwan for providing the data. We also wish to acknowledge the very useful and constructive comments and discussions from Yiping Hsu and the seminar participants of the 2013 WEAI International Conference in Seattle, USA. Financial support from the National Science Council of Taiwan in the form of grant NSC 100-2410-H-007-025-MY2 is greatly appreciated.
} 


\section{Introduction}

With the ongoing trend towards globalization, economic competition between countries hinges heavily on research and development $(\mathrm{R} \& \mathrm{D})$ and innovation. Since the number of PhD graduates is the most important potential source of researchers, the public authorities have been making every effort to vigorously promote doctoral programs 1 The rapidly increasing number of $\mathrm{PhD}$ graduates has led to an excess supply in the highly-qualified labor market, especially for the academic labor market $L^{2}$ Townsend (2012) further reports that less than half of new recipients of doctoral degrees had a full-time job in the U.S. in 2010. In order to encourage doctoral graduates to take up non-academic employment, Cyranoski et al. (2011) note that Japan's Ministry of Science and Education offers companies around US $\$ 47,000$ each to hire postdoctoral students. They also point to the decreasing pattern of full-time tenured positions or the tenure track of employment of doctoral degree holders as well as the increasing number of postdoctoral positions in the U.S 3

A postdoctoral position is a special transitional position that is only eligible for those with a doctoral degree. Taking up a postdoctoral position could be interpreted in many ways and has different functions and meanings in the literature. According to the National Postdoctoral Association (NPA), a postdoctoral scholar (postdoc) is defined as "an individual holding a doctoral degree who is engaged in a temporary period of mentored research and/or scholarly training for the purpose of acquiring the professional skills needed to pursue a career path of his or her choosing." That is, the training in research when working in a postdoctoral appointment can be seen as an investment to accumulate the additional human and social capital needed to facilitate the future job search in a deteriorating labor market (Robin and Cahuzac, 2003; Stephan and Ma, 2005; Recotillet, 2007; Schwabe, 2011) 4 Getting involved in postdoctoral

\footnotetext{
${ }^{1}$ For instance, in the 1990s, the Japanese government set a goal of raising the number of postdocs to 10,000 (Cyranoski et al., 2011). Such a policy has been designed to enable the number of PhDs in Japan to catch up with those in Western countries. The provision of grants for running PhD programs has doubled within 4 years in France (Mangematin, 2000). In the U.S., academic institutions awarded 48,069 research doctorates in 2010 compared to 41,372 in 2000 (Fiegener, 2011). According to a report written by Cyranoski et al. (2011), "the number of science doctorates earned each year grew by nearly 40\% between 1998 and 2008, to some 34,000, in countries that are members of the Organisation for Economic Co-operation and Development (OECD)."

${ }^{2}$ We focus on the supply side of doctoral holders, rather than on the demand side that is analyzed by Cantwell and Taylor (2013). We note that only about one-quarter of all doctoral degree holders are employed in academic positions after their $\mathrm{PhD}$ training (Neumann and Tan, 2011). In addition, the opportunities for tenured-track assistant professor positions have declined by 40 percent in less than 10 years in France (Recotillet, 2007), implying that it is getting more difficult for $\mathrm{PhD}$ graduates to find a job that matches their rigorous academic training. Jackson and Michelson (2014) explore the factors that influenc initial post-graduation job attainment of Australian $\mathrm{PhD}$ graduates based on a national survey conducted in 2011 and 2012.

${ }^{3}$ According to Cyranoski et al. (2011), "in 1973, 55\% of US doctorates in the biological sciences secured tenuretrack positions within six years of completing their PhDs, and only $2 \%$ were in a postdoc or other untenured academic position. By 2006, only $15 \%$ were in tenured positions six years after graduating, with $18 \%$ untenured."

${ }^{4}$ Igami et al. (2014) indicate that postdoctoral fellows play an important role in scientific research. They could not only shorten the mean citation time lag in the highly cited papers but also produce more highly cited papers compared to normal papers.
} 
positions may also be necessary as a probation period for becoming a researcher in some fields, such as life sciences or biochemistry (Nerad and Cerny, 1999; Stephan and Ma, 2005; Recotillet, 2007; NPA, 2011). Several studies traditionally note that the postdoctoral experience should enhance the chances of finding a job in research (Hanchane and Recotillet, 2003; Recotillet, 2007; McAlpine and Emmioğlu, 2014). Understanding how postdoctoral training affects subsequent career outcomes is an urgent task for both academic researchers and policy-makers, not only because it could shape the individual willingness of prospective participants, but because it could also detect the potential capacity of the research workforce (Su, 2013).

With the deregulation of the education system in the early '90s $5^{5}$ the number of $\mathrm{PhD}$ recipients in Taiwan has dramatically increased from 410 (1989) to 3,846 (2010) over the past 20 years, an amazing growth exceeding $800 \% \sqrt{6}$ Meanwhile, the number of students enrolled in $\mathrm{PhD}$ programs in Taiwan has also expanded sharply from 3,799 in 1989 to 34, 178 in 2010 (Lin and Chiu, 2014). The existing job vacancies in both the private and public sectors are making it difficult to accommodate the new PhDs. Therefore, the over-supply of doctoral degree holders in Taiwan has revealed a sharp increase in the number of candidates seeking postdoctoral positions in recent years. According to statistics reported by the National Science Council (NSC) in Taiwan, the number of $\mathrm{PhD}$ graduates applying for postdoctoral positions increased from 1,109 in 2007 to 3,593 in 2011:7 Given the prevailing situation of postdoctoral positions nowadays, it is crucial to explore the role played by postdoctoral participation in the post-PhD labor market. However, not too many studies in the literature have focused on postdocs, even though some researchers have focused attention on the labor outcomes of PhDs (being an academic researcher or not) and changing career trends (from universities or the public sector to the private sector) (Recotillet, 2007; Neumann and Tan, 2011). One possible reason for the lack of research in this area is the scarcity of data for over a decade in regard to postdocs (Hanchane and Recotillet, 2003).

This article attempts to investigate the relationship between the postdoctoral experiences of $\mathrm{PhD}$ holders and their job choice. Our contribution to the literature is threefold. First, we have compiled a comprehensive data set (the National Profiles of Human Resources in Science and Technology in Taiwan) which consists of a large number of doctoral degree holders with their postdoctoral status $(N=22,412)$, covers $\mathrm{PhD}$ holders across different disciplines, and spans a long period of time ranging from 1920 to 1980 in terms of the birth cohorts. Second,

\footnotetext{
${ }^{5}$ Upon the lifting of Martial Law in 1987, higher education in Taiwan entered a period of drastic change alongside the introduction of a market mechanism to the education system in the early '90s. The passing of the 1994 University Law aimed to reduce the power of the central government by granting academic autonomy and institutional flexibility to universities. Taiwan has since experienced an unprecedented expansion of higher education, reflected by a sharp increase in the number of universities (both undergraduate and graduate programs) as well as student enrollments.

${ }^{6}$ Data source: http://www.edu.tw/statistics/index.aspx

${ }^{7}$ The most renowned research institute in Taiwan, Academia Sinica, faced a similar trend in the sense that the approval rate for being a postdoctoral fellow in Academia Sinica declined from 86\% (134 out of 156 applicants approved) in 2002 to $29 \%$ (115 out of 391 applicants approved) in 2012.
} 
using a control function Probit approach, we are able to address the potential endogeneity issue of engaging in a postdoctoral position. More specifically, we first explore the characteristics of the first job choice of fresh $\mathrm{PhD}$ holders, that is, the choice between a postdoctoral position and other full-time jobs. Then, we evaluate the effect of gaining a postdoctoral experience endogenously on their current job choice regarding academic and non-academic positions. Third, taking advantage of our large sample size, we explore the heterogeneous effect of the postdoctoral apprenticeship for acquiring more knowledge and getting more practical experience on the academic/non-academic job choice. This is executed by splitting the entire sample into several sub-samples by gender, major and birth cohort. A series of sensitivity analyses are also performed to confirm our empirical findings 8

The rest of this paper is structured as follows. Section 2 outlines the theoretical framework associated with the effects of postdoctoral experience on the choices of academic jobs, and Section 3 briefly discusses the related literature. The data and statistical methods are described in Section 4. We then present and discuss the empirical results in Section 5. The final section concludes the paper by offering additional remarks.

\section{Theoretical Framework}

According to the discussion in Section 1, previous studies have tended to argue that engaging in a postdoctoral position is positively associated with earning a tenure track job in academia. Several existing theories do suggest a positive relationship between engaging in postdoctoral work and advancing to academia, while some may not support this argument. In the following, we present the pros (human/social capital theory and education signaling theory) and cons (the refuge-seeking jobs argument) theoretically.

\subsection{Human/Social Capital Theory}

Postdoctoral training is an extension of $\mathrm{PhD}$ education and can be regarded as an educational investment in human and social capital to facilitate the acquisition of future research jobs (Robin and Cahuzac, 2003; Stephan and Ma, 2005; Recotillet, 2007; Schwabe, 2011). As for human capital accumulation, the training process not only improves or develops research skills and abilities, but also enables the researchers to gain experience related to publications (Recotillet, 2007; Su, 2013; Ghaffarzadegan et al., 2013). In particular, Horta (2009) points out that the reason why postdoctoral experience brings benefits in terms of advancing to academia may be due to the greater research output of academics which is fostered in a postdoctoral position. Engaging as a postdoc is usually seen as a necessary step or a required probation period in order to have sufficient training to obtain an academic position, just like an apprenticeship in

\footnotetext{
${ }^{8}$ We have prepared an online supplementary appendix, which contains a series of sensitivity analyses and additional results omitted from the main paper.
} 
some other fields, such as the life sciences or biochemistry (Nerad and Cerny, 1999; Stephan and Ma, 2005; Recotillet, 2007; NPA, 2011). From a social capital perspective, the postdoctoral position provides opportunities to expose those with $\mathrm{PhD}$ degrees to more professional networks (Su, 2013). During the postdoctoral training period, $\mathrm{PhD}$ holders have more funding to get involved in the academic community (e.g., by participating in seminars and conferences), have more occasions to get acquainted with leading scholars in their field, and have more chances to collaborate on projects. Bonnal and Giret (2008) also argue that postdoctoral positions provide opportunities for $\mathrm{PhD}$ graduates to discover a new environment and express their ability to work well in a team. All these activities are beneficial in augmenting the doctorates' academic network from their own PhD program to the entire profession. In sum, the postdoctoral experience will facilitate access to the academic teaching/research areas as predicted by human capital theory.

\subsection{Education Signaling Theory}

Based on the signaling theory in Spence (1973), Recotillet (2007) points out that participation in a postdoctoral program could serve as an instructive signaling mechanism to reduce imperfect information regarding a candidate's ability, and thus increase the probability of being recruited as a researcher. In particular, if a newly-minted doctoral degree holder did not receive his/her $\mathrm{PhD}$ degree from a prestigious university, it would be an incentive for him/her to engage in a postdoctoral training program to reveal his/her ability. Another way to constitute the postdoctoral signal is through activities that are valued in the recruitment procedure, such as publications in high-ranking journals during the postdoctoral period. Through such upgrading, it is much easier for postdoctoral fellows to find a better academically-oriented position later on. Signaling theory also suggests that those who are more capable in research have a greater tendency to take up postdoctoral positions since their embedded cost is much lower than that of those with less ability. That is, less capable doctoral degree holders will turn to other sectors (e.g., government) as opposed to choosing postdoctoral positions. In addition, postdoctoral experience could be viewed as a valuable credential to screen an individual's greater motivation and stronger research commitment to potential employers ( $\mathrm{Su}, 2013)$, which supports the socalled credential inflation theory (Collins, 1979; Spence, 1973). This perspective matches the signaling theory in that fresh $\mathrm{PhDs}$ attempt to convey a signal to distinguish themselves from others by taking up postdoctoral positions. Once again, the education signaling theory suggests that there is a positive impact of engaging $\mathrm{PhD}$ degree holders as they transition towards job in academia.

\subsection{Refuge-seeking Jobs Argument}

With the expansion of higher education along with a significant reduction in academic positions,

doctorates face a severe job market. It is very difficult for a fresh $\mathrm{PhD}$ to secure a tenure track position. In this case, a postdoctoral appointment may be one of their better choices (Recotillet, 
2007). Supposing that those tenure track jobs are filled up with highly-talented holders of fresh doctorates, the less capable candidates will have to take up the temporary postdoctoral positions. $\mathrm{Su}$ (2013) also points out that "one theory suggests if postdoctoral training could no longer promise good prospects of a prestigious faculty job, the positions would be filled with less promising candidates who take the positions as the best alternative due to the lack of employment opportunities from nonacademic sectors (Zumeta, 1985)." The above arguments imply that if the less talented $\mathrm{PhD}$ holders engage in postdoc or postdoctoral training, it will not be possible to attract promising young scholars, indicating that those who have postdoctoral experience may not be sufficiently useful to fill future jobs in the academic area. This "refuge-seeking jobs argument" indicates that postdoctoral jobs act like a temporary refuge for unemployed doctoral degree holders (CPST, 2002; Stephan and Ma, 2005). In sum, the refuge-seeking jobs argument implies that choosing a temporary postdoc position is not beneficial to the placement of suitably qualified academics in education institutions.

\section{Literature}

With the surge in the number of postdoctoral appointments. 9 the effects of such temporary work experience on the future career development of new PhD holders are not sufficiently clear to policy-makers or academic researchers or even to the graduating doctoral students themselves. This may be because of the temporary status of postdoctoral positions, or the varying responsibilities and rights that make the role of postdoctoral positions less visible and less studied (Cantwell and Lee, 2010). Even though an increasing number of statistical reports on doctorate recipients involved in postdoctoral positions have been collected by government organizations or universities in recent years, systematic analyses of $\mathrm{PhD}$ job choices vs. postdoctoral experience are relatively limited.

The decision to enter a postdoctoral program is a non-random selective process that depends on the individual's characteristics (Stephan and Ma, 2005). Many dimensions would affect the probability of participating in a postdoctoral program. Stephan and Ma (2005) report that older individuals, females, married respondents, and number of dependents have negative effects on the choice of postdoctoral positions estimated by a logit equation. These results may reinforce the theory that postdoctoral training is viewed as an investment in additional capital. Similar results found in Recotillet (2007) reveal that not only personal factors, but also educational background, such as the time of graduation, discipline, financial support, as well as the place where the doctoral training took place, will all affect the decisions made regarding postdoctoral appointments. Recotillet (2007) also introduces the correlation between the time of graduation and the participation in postdoctoral programs. Bonnal and Giret (2008) indicate

\footnotetext{
${ }^{9}$ According to a report of the NSF, the number of postdoctoral appointees majoring in science and engineering has increased from 19,000 to 32,000 in just fifteen years (Stephan and Ma, 2005). The number of postdocs in the U.S. has increased about 27 percent between 1998 and 2007 (Cantwell and Lee, 2010).
} 
that being awarded a postdoctoral position strongly depends on factors including the fields of study, financial support, graduating institutions, the number of publications, and the time taken to complete the doctoral degree. In addition, the candidate's citizenship status also affects the propensity for taking on a postdoctoral position (Stephan and Ma, 2005; Corley and Sabharwal, 2007; Lan, 2012). It could be that those who have temporary visas (e.g., foreign students) are more likely to take a postdoctoral position relative to citizens or permanent residents in the U.S. due to visa restrictions.

Previous studies have attempted to investigate whether postdoctoral experience would increase the chances of landing a faculty job. Using a sample of 800 young French doctorates in the life sciences, Robin and Cahuzac (2003) find that taking up a postdoctoral position seems to be an efficient stepping stone towards lifetime public academic employment. Recotillet (2007) analyzes the early careers of French PhD graduates in science and engineering in 1996 and finds that postdoctoral experience plays a much more important role in the choice of career than the wage premium. In considering young $\mathrm{PhD}$ degree holders in French universities, Hanchane and Recotillet (2003) find that postdoctoral experience increases the probability of obtaining a research job in the public sector for those majoring in natural sciences. Similarly, there may be a positive return from postdoctoral experience in terms of moving up the job queue for permanent positions in France after controlling for the endogeneity of postdocs and unobserved heterogeneity, as reported by Bonnal and Giret (2008). Åkerlind (2009) conducts an online survey of 1,011 postdocs in Australia and finds that about $73 \%$ of the postdoctoral respondents would like to pursue an academic position. Overall, the decision to take up a postdoctoral position is better suited to those pursuing academic careers.

Nevertheless, in the literature, the postdoc effect is not always found to be positive in terms of advancing towards an academic job. According to Cantwell and Lee (2010), there is an increasing number of PhDs who undertake postdoctoral positions, but few of them eventually obtain tenuretrack faculty positions. The ratio of biological sciences doctorates employed as faculty members has dropped from over 80 percent to about 40 percent from 1973 to 1999. Musselin (2004) indicates that in the European academic labor market, it is common to employ postdocs from abroad but fewer international postdocs eventually become their future faculty members. As pointed out by Orfeu Buxton 10 the postdoc has become an "obligatory credential, necessary but not sufficient to establish a young investigator's potential for other independent research jobs" (Goldman and Marshall, 2002). Hanchane and Recotillet (2003) find that postdoctoral experience has a negative effect on obtaining a research job for French $\mathrm{PhDs}$ in the humanities and social sciences. These studies may imply that the postdoctoral career trajectory is no longer a means of obtaining faculty jobs.

Although postdoctoral positions are conventionally recognized to apply to graduates who

\footnotetext{
${ }^{10}$ A University of Chicago postdoc and one of the founders of the fledgling National Postdoctoral Association. Data source: http://www.sciencemag.org/content/298/5591/40.full.
} 
wish to enter the public research sector, recently a significant number of $\mathrm{PhD}$ graduates who engaged in a postdoctoral program were employed in the private sector a few years later. Several studies have focused on the job choices of $\mathrm{PhD}$ degree holders between the public and private sectors (Robin and Cahuzac, 2003; Portnoi, 2009; Schwabe, 2011), but there is less concern with the career trajectory a few years later. That is, the effect of postdoctoral experience on the future career development across different sectors has not yet been well explored. Stephan (2009) notes that "many PhDs only take jobs in industry after failing to find an academic position after serving as a postdoc for four or five years." According to Recotillet (2007), the postdoctoral training will not bring any significant advantage to wages in the private sector, which favors the refuge-seeking jobs argument described in Section 2 whereby participation in a postdoctoral program occurs only because fresh $\mathrm{PhDs}$ do not have any better job opportunities.

Compared to previous studies, our project uses a relatively large data set covering a long span of time and includes a variety of fields of study. The initial job choice and current job placement are also carefully recorded. We can therefore not only analyze the factors that affect the first job choice, especially when considering the postdoctoral positions, but we can also estimate whether the postdoctoral experience is beneficial to the doctoral degree holder's career in relation to academic positions, government jobs, or industrial employment.

\section{Data and Statistical Method}

\subsection{Data Description}

To conduct our empirical investigation, we draw the data on $\mathrm{PhD}$ recipients from the National Profiles of Human Resources in Science and Technology (NPHRST) compiled by the Science and Technology Policy Research and Information Center of the National Applied Research Laboratories in Taiwan. NPHRST aims to gain a better understanding of the science and technology higher education manpower, and to build up a long-term observation mechanism for high-level manpower predictions, which can provide the current situation and mobile information concerning higher education with the Taiwanese government for policy-making purposes, such as the selection of specialized personnel and the adjustment of the balance between the supply of and demand for human resources. Since 2002, NPHRST has collected data annually through sending e-mails to those who have completed their PhD degrees, where the potential respondents have been drawn from scholars/researchers registered in the following five sources: National Science Council (NSC) research personnel that are part of the government research plan, the Government Research Bulletin (GRB), the Database of Research and Innovation Capacity (DBRIC), the National Digital Library of Theses and Dissertations, and official web sites of universities, colleges, and research institutes in Taiwan ${ }^{11}$ For each year, new respondents will be included in

\footnotetext{
${ }^{11}$ Among these channels, those who work outside the academic area but collaborate with any researchers in academic institutions funded by government would also be contained in the investigation pool. According to the
} 
the data set. The most recent data set that we obtained from NPHRST was that for September 2010. The current sample reveals that the respondents' ages range from 30 to 90 (i.e., 1980 to 1920 birth cohorts), even though most of them were born between 1950 and 197012

The NPHRST questionnaire covers a series of doctoral degree holders' labor market outcomes, which is the basis of our dependent variable. The labor market outcome questionnaire explicitly asks the respondent "What is your initial job choice after receiving a doctoral degree?" and "What is your current job?". The initial job choice for a recent $\mathrm{PhD}$ degree holder can be divided into a postdoc position and other types of jobs. Whether or not to engage in a postdoctoral position is our first outcome variable. The respondents' current job status (e.g., academia, or non-academic) is also recorded in the survey. In order to examine the impact of postdoctoral experience on choosing an academic job, the second outcome variable is constructed as currently being in academia or in other sectors. Here, the academic position that is defined in our paper contains all research-oriented jobs, including those in academia as well as research positions in government 13 while the non-academic jobs refer to those not engaging in research in government and in industry. Note that we do not consider those who work for private non-profit/international organizations in Taiwan, where the number of observations is quite limited.

In this study, we also consider as many explanatory variables as possible which may affect our two outcomes in order to control for differences in the outcomes related to the differences in these variables. Some important job choice characteristics have been well recognized in the literature (Rubin and Cahuzac, 2003; Stephan and Ma, 2005; Recotillet, 2007) and may be categorized into two broad groups, namely, demographic and academic characteristics.

\section{Demographic characteristics:}

The age obtaining a $\mathrm{PhD}$ degree has been considered in the literature (Recotillet, 2007). In addition, by taking advantage of our data with a long time span, we are able to categorize four different cohorts to evaluate their effect on postdoc engagement and different job choices. Incorporating the cohort dummies is in order to partially control for the possible impact of the period of time on the post-PhD job choice. Gender is taken into consideration as well since males and females inherit different personality traits and may act very differently under social

official report by NPHRST, the returning rate is about $13 \%$. It is also worth noting that NPHRST only surveyed the PhD holders that stay in Taiwan. For those who studied abroad and worked overseas after receiving their PhD degrees, NPHRST is not able to keep track of them. There may also be a potential selection bias such that those without academic jobs were not inclined to participate in the NPHRST survey. These issues can be regarded as the data limitation of our research and deserve a further exploration.

${ }^{12}$ Since our sample covers a long time span, it may mask significant changes in postsecondary institutions worldwide as underscored by recent developments in postsecondary institutions in Europe triggered by the Bologna Accord (in particular for those receiving the PhD degree from Europe). To alleviate the impact of the Bologna Accord on our results, we re-estimate our model for those graduated after year 2000 and reach very similar conclusions. Please refer to the online supplementary appendix.

${ }^{13}$ Note that we also restrict our definition of "academic jobs" to those in educational institutions only by excluding those people doing research in government for the sensitivity analysis, which leads to a very similar result. Please refer to the online supplementary appendix for more details. 
norms (Siegfried and Stock, 2001; Stock et al., 2009).

\section{Academic characteristics:}

The location of the doctoral degree granting universities is likely to be an important factor affecting job choice even though the relationship is not clear-cut. We particularly distinguish the graduate schools with $\mathrm{PhD}$ programs that are located in Taiwan or in other countries. Elapsed time to a doctoral degree is also a potential factor that may affect the future job choice of PhD holders (Recotillet, 2007; Bonnal and Giret, 2008). The fulfillment of the requirements for the degree of $\mathrm{PhD}$ varies across the fields of study, and is associated with different levels of paradigms and in turn is likely to influence the labor market choice. We thus consider the following eight disciplines: (1) humanities and the arts, (2) social sciences, business and law, (3) science, (4) engineering, manufacturing and construction, (5) agriculture, (6) health and welfare, (7) services and (8) education, with education being the reference major ${ }^{14}$ School quality is often a concern associated with job choice. In order to consider the school quality for overseas and domestic universities as a whole, we follow the Academic Ranking of World Universities (ARWU) to screen out the top 30 universities in the world 15 The search time to the first job after receiving a $\mathrm{PhD}$ degree is constructed and included in our empirical model. The time of graduation (graduation season being constructed in our sample) usually matters for the job search and is also considered as well. The detailed definitions of the above descriptive variables are listed in Table 1 .

When the duration of the degrees (e.g., doctoral, master's or bachelor's degrees) for a respondent is negative, we drop the resulting observation ${ }^{16}$ In addition, we do not consider those who pursue their study in China since the sample size is too small to group them in our subsequent empirical analysis, and in any case they do not have any bearing on our results. The $\mathrm{PhD}$ recipients who do not classify their schools are also excluded from the sample because one of our concerns in regard to the outcome variables is school quality, such as the global ranking of universities/colleges. Furthermore, we delete the respondents who are less than 10 years old, reflecting the belief that they are too young to obtain a doctoral degree ${ }^{17}$ We further delete observations with missing values and logical inconsistencies, and end up with a total of 22,412 observations in our sample.18

\footnotetext{
${ }^{14}$ The disciplines in the "services" category include fields of study such as Hotel and Catering, Travel and Tourism, Sports, Sport Science and Technology, Sports and Leisure, Beauty Treatment, Railway Operations, Road Motor Vehicle Operations, Air Crew, Air Traffic Control, Nautical Science, Ship's Officer, Postal Service, Civil Security, Military, and other services.

${ }^{15}$ ARWU can be accessed at the following website: http://www.arwu.org/index.jsp.

${ }^{16}$ Note that we do not delete those having an elapsed time to a degree (ETTD) of less than 2 years or longer than 10 years, since it is difficult to judge whether the reported ETTD is reasonable or not. However, we have experimented with a series of sensitivity analyses that trim extreme values based on different cut-offs and have found very similar results.

${ }^{17}$ Since those observations are relatively few (in fact, there are only six respondents), the estimation results remain unchanged when we perturb the cut-off age (10 years) slightly.

${ }^{18}$ The missing data, for instance, include those failing to report gender, field of study, school type, year of admission, year of graduation, and so on.
} 


\subsection{Descriptive Evidence}

The summary statistics of the continuous variables are presented in Table 2 . The average time taken to complete a doctoral degree for our entire sample is 4.76 years, which is less than the 6.8 years reported by Picciano et al. (2008) using U.S. data. In considering the higher education system in Taiwan, it is quite normal for pupils to hold both bachelor's and master's degrees before entering a $\mathrm{PhD}$ program. Around $88 \%$ of Taiwanese pupils hold a master's degree before entering a doctoral program, while only $12 \%$ have a bachelor's degree only. Thus, the entire learning process towards obtaining a $\mathrm{PhD}$ degree in higher education for Taiwanese students lasts approximately 10.4 years 19 which is close to that in Hoffer et al. (2006) - the median time of all fields was 10.1 years from a bachelor's to a doctorate for those U.S. doctoral degree recipients in 2003.

The mean age of respondents completing a doctoral degree is about 33.85 years old with the youngest being 22 and the oldest being 59 years old. Note that Hoffer et al. (2006) point out that the median age upon the receipt of a doctorate is 33.3 years across all fields in the U.S., which is very close to the statistics calculated using Taiwanese data. When we separate our data by cohorts, it is found that the recent cohorts tend to finish their $\mathrm{PhDs}$ at a younger age. In addition, the youngest cohort spends about 0.55 years obtaining their first jobs, which is less than that for the older cohorts (who take about 0.64 or 0.65 years).

Table 3 provides a summary of the $\mathrm{PhD}$ graduates' first job choice in terms of the percentage shares. About $14.89 \%$ of our sample choose a postdoctoral position as their first job. The proportion of those engaging in postdoctoral positions is higher for younger cohorts compared to older cohorts (the ratio rose sharply from $8.69 \%$ to $21.74 \%$ ). A sharp increase in the share of newly-minted $\mathrm{PhD}$ recipients heading on to postdoctoral appointments has also been found in Townsend (2012). PhDs with science majors have the highest propensity of holding postdoctoral positions (around 39.51\%), which is along the lines of Hanchane and Recotillet (2003) in that about $45 \%$ of natural and life sciences graduates engage in postdoctoral programs. About half (i.e., 49.93\%) of the PhDs graduate during the second quarter (see Table 3). This is different from what was found in Recotillet (2007), where about $40 \%$ of students graduate during the last quarter. Besides, those who graduated in the second quarter have the lowest ratio of being postdocs $(13.87 \%$ in the second quarter against $17.19 \%$ for those who graduated in the fourth quarter).

The frequencies associated with current jobs among the two sectors (academic and nonacademic) are listed in Table 4, showing that there are a large number of doctorates working in academic positions (around $94.11 \%=21,091 / 22,412$ in our data). This number is remarkably higher than that in previous studies, e.g., Neumann and Tan (2011) reveal that less than half of new doctoral degree holders pursue an academic career with the emerging knowledge

\footnotetext{
${ }^{19}$ Note that this number is obtained by summing 4.4 median years, consisting of the typical 2 years for a master's degree and 4 years for a bachelor's degree.
} 
economy in the U.S. and Australia. Table 4 also shows that more males (7.17\%) work in nonacademic institutions relative to females (1.69\%). The youngest cohort (12.44\%) tends to work in non-academic institutions compared to the oldest (only 3.62\%). Besides, those who graduated from domestic schools (including private and public universities in Taiwan) or who majored in Engineering are more likely to be in non-academic jobs. The second highest proportion in non-academic institutions consists of those majoring in science with a ratio of about $6.27 \%$.

\subsection{Empirical Methods}

In order to analyze a dichotomous choice for the decision to participate in a postdoctoral program, a typical binary choice model is applied. The two choices in regard to the initial jobs after graduation include a postdoctoral position and other full-time jobs. When we consider the current job choices between academic or non-academic positions, the binary choice model is also a reasonable specification. Specifically, the random utility model is formulated as follows:

$$
I_{i}^{*}=X_{i}^{\prime} \beta+u_{i}, I_{i}=1 \text { if } I_{i}^{*}>0
$$

where $I_{i}^{*}$ is the latent utility for the decision to make an initial job choice between a postdoctoral position and other full-time jobs or the current job choices between academic and non-academic positions. $X_{i}$ is the vector of the corresponding explanatory variables. $I_{i}$ denotes the observed individual choice. When estimating the propensity to engage in a postdoctoral position for a new $\mathrm{PhD}$, the explanatory variables include the duration of pursuing the $\mathrm{PhD}$ degree, the age when receiving the $\mathrm{PhD}$ degree, the search time for the first job, gender, school type, major, cohorts, school rankings, time of graduation, and so on.

Our main empirical investigation is to evaluate the impact of the postdoctoral experience $\left(I_{i}\right)$ on the propensity to obtain an academic job for a $\mathrm{PhD}$ graduate. It is possible that less capable and/or less motivated doctorates may choose other alternatives (e.g., government) rather than considering postdoctoral positions. Thus, including the postdoctoral experience as an independent variable may give rise to an endogenous binary regressor and lead to inconsistent estimates. The current job choice equation can be specified as follows:

$$
Y_{i}^{*}=\gamma I_{i}^{*}+Z_{i}^{\prime} \delta+v_{i}, Y_{i}=1 \text { if } Y_{i}^{*}>0
$$

where $Y_{i}^{*}$ is the latent utility for the decision regarding the current job choices between academic and non-academic positions. $Y_{i}$ denotes the observed individual choice, $I_{i}^{*}$ is the endogenous decision regarding initial job choices between postdoctoral positions and other full-time jobs, and $Z_{i}$ is the vector of the explanatory variables similar to those in $X_{i}$. Notice that we include graduation seasonal dummies in (1), which are believed to be correlated with the initial job choice but not the current job in academia or non-academia. In addition, the graduation seasonal dummies can be regarded as the instrumental variables or exclusion restrictions. 
The usual "two-step" estimation procedure to obtain the regression coefficient in (2) does not produce consistent parameter estimators for this type of nonlinear model, that is, when estimating the Probit in (1) and plugging the fitted value (i.e., $\left.\hat{I}_{i}\right)$ in (2) to estimate the second stage Probit (on this see Imbens and Wooldridge (2007)). Thus, we use the control function approach suggested in Imbens and Wooldridge (2007) to deal with the possible endogeneity problem of engaging in postdoctoral work when estimating the effects of postdocs on the current career choice between academic and non-academic jobs. The control function approach includes two steps: the first step is to fit equation (1) through OLS and obtain the residual $\hat{u}$; and the second step is to estimate (2) by a standard Probit model with regressors $I^{*}, Z$, and $\hat{u}$. Another advantage of this simple approach is that it allows us to check the exogeneity of engaging in a postdoctoral position by testing whether the coefficient of $\hat{u}$ is zero or not.

Figure 1 outlines the structure of our empirical applications. The top panel starts with our two-step estimation procedure to tackle the potentially endogenous engagement in postdoctoral positions. The three heterogeneous effects of the postdoctoral experience on academic or nonacademic job choice are estimation (to be introduced in Section 5.3). To ensure the robustness of our empirical finding, we perform a series of sensitivity tests, which include different definitions of "academic job", the cutoff age obtaining a $\mathrm{PhD}$, the year of graduation, and so on (see an online supplementary appendix).

\section{$5 \quad$ Empirical Results}

\subsection{Engaging in Postdoctoral Work or Other Full-time Jobs?}

In order to find the factors that influence the seeking of postdoctoral positions and the changing pattern over different cohorts, Table 5 presents the estimation results based on the Probit model of participating in a postdoctoral position or other full-time jobs as the initial job choice after receiving $\mathrm{PhD}$ degree.

Table 5 shows that the longer time spent by doctoral degree holders to complete their thesis tends to increase the probability of participating in a postdoctoral program as their first job. It is likely that a longer ETTD may be a bad signal and that the candidate cannot but take up a postdoctoral position after being awarded a $\mathrm{PhD}$ degree. Those obtaining the doctoral degree at a later age are less likely to go for a postdoctoral position, which is consistent with the previous literature (Hanchane and Recotillet, 2003; Stephan and Ma, 2005). Stephan and Ma (2005) point out that doctorates are less likely to take a postdoctoral position to invest their human capital if there is a shorter expected career. Besides, older graduates have heavier family duties than younger ones. The friction between postdoctoral projects and family plans will decrease the willingness to be a postdoctoral fellow (Robin and Cahuzac, 2003; Stephan and Ma, 2005; Recotillet, 2007).

Thanks to our abundant data with its long time span, we include three cohorts in our 
model (born before 1960, born between 1960 and 1969, and born after 1970). Table 5 indicates that the younger cohort is more likely to take a postdoctoral position as the first job. One possible explanation is that a temporary postdoctoral position is better than unemployment when highly-qualified manpower enter the labor market, which has resulted in an excess supply in recent decades ${ }^{20}$ Cyranoski et al. (2011) mention that "in 1973, 55\% of US doctorates in the biological sciences secured tenure-track positions within six years of completing their PhDs, and only $2 \%$ were in a postdoc or other untenured academic position. By 2006, only $15 \%$ were in tenured positions six years after graduating, with $18 \%$ untenured." Besides, going through a postdoctoral position is a way of reaping academic benefits from further investment in a deteriorating labor market (Recotillet, 2007). The mechanism may help explain the tendency that an increasing number of graduates choose a postdoctoral position as their first jobs at the time of their graduation.

By setting the major of Education as the reference group, the coefficients of other subjects are statistically positive, except for Social Science (in Model 1 and Model 2 of Table 5). Compared with the coefficients for majors, those majoring in Science are more likely to engage in postdoctoral work while those majoring in Social Science are less likely to do so. This observation is quite similar to Schwabe (2011) in that a postdoctoral appointment is a necessary step in some research careers, especially for those majoring in Science. All of the interaction terms of school types and subjects are positive, although most of the coefficients are insignificant, which may imply that those studying overseas and majoring in Education are less likely to take up postdoctoral positions.

Those who earned their PhDs from better institutions (the top 30 universities in the world) tend to become postdoctoral fellows because they are more research-oriented and willing to invest in themselves for future academic positions. Compared to females, males have a greater tendency to choose a postdoctoral position as their first job after graduation, which is in accordance with Stephan and Ma (2005). This may suggest that stable jobs rather than temporary jobs (e.g., a postdoctoral position) are more attractive for female doctorates. In addition, the time of graduation also matters. In Taiwan, the second season usually provides the most job opportunities, and so doctoral degree holders are able to choose among other full-time positions and in turn are less likely to participate in a postdoctoral position. The inclusion of the interaction terms between majors and obtaining a PhD degree overseas in Models 3 and 4 of Table 5 does not significantly change our main results.

We have demonstrated some important factors associated with a $\mathrm{PhD}$ degree holder's first job choice, while the Probit coefficients do not reflect the marginal effect of a specific covariate.

\footnotetext{
${ }^{20}$ According to the 2014 report by the Directorate-General of Budget, Accounting and Statistics in Taiwan, the unemployment rate was relatively low in most countries before 2010. For example, the unemployment rate in Taiwan was about $1.7 \%$ in 1990 and $3.0 \%$ in 2000 . For the U.S., the unemployment rate was between $5.6 \%$ and $4.0 \%$ during the period 1990 to 2000 . It was between $6.9 \%$ and $5.4 \%$ for the same period in the U.K. However, in 2010, the unemployment rate rose sharply, e.g., $5.2 \%$ in Taiwan, $9.6 \%$ in the U.S. and $7.8 \%$ in the U.K. See http: //www . dgbas.gov.tw/ct_view . asp?xItem=35670\&ctNode=3247 for more details.
} 
By inspecting the marginal effects in Table 5, it is found that among these variables with statistically significant influence, discipline plays a crucial role in determining a postdoctoral choice. For example, those majoring in Science have roughly $45 \%$ of the probability of choosing postdoctoral positions as their initial jobs relative to Education majors, ceteris paribus. For those majoring in Agriculture and Health, the probabilities of engaging in postdocs are also up to $38 \%$ and $33 \%$ higher than for those in Education, respectively (see Model 1 in Table 5. In addition to the disciplines, cohort has some great impacts. The youngest cohort (born after 1970) has a higher probability (by 12\%) of engaging in postdoctoral work relative to the oldest cohort, and the mid-cohort (born between 1960 and 1970) has a $7 \%$ higher probability of engaging in postdoctoral work. Besides, other variables have a relatively small influence in terms of magnitude even though they might be statistically significant in terms of their coefficients.

\subsection{Does Postdoctoral Experience Lead to an Academic Career?}

In regard to the role of experiencing a postdoctoral position played upon entering an academicallyoriented job, our finding in Table 6 indicates that the postdoctoral experience significantly raises the probability of advancing in the academic sector, holding other factors constant. Models 1 and 3 include the foreign variable to take into account the fact that around $50 \%$ of Taiwanese doctorates obtain their degrees overseas. Models 2 and 4 further classify the graduation schools of the locally trained PhDs into Taiwanese public and private universities. Note that Models 1 and 2 simply adopt the Probit approach without considering the possible endogenous choice of postdoctoral positions, while Models 3 and 4 utilize the control function approach to deal with the potential endogeneity issue. The coefficient of the residual $(u)$ estimated from the first stage is significantly different from zero at the $1 \%$ level, which justifies the importance of considering the endogenous decision of postdoctoral engagement (see Models 3 and 4 of Table 6).

According to the significantly positive coefficient of postdoctoral positions, the further educational investment (i.e., postdocs) seems valuable for doctoral degree holders to stay in academic careers later on. Building on the human capital theory, the postdoctoral training increases the probability of entering academic institutions probably through improving the research abilities and gaining publishing experience with peers and advisors. If we use the prediction of education signaling theory, taking postdoctoral positions could be viewed as a good signal to screen an individual's greater motivation and stronger research commitment. Since we do not have sufficient information on the research funding or papers of a postdoc, we can only claim that the human capital and education signaling theories are "indirectly" supported in this article ${ }^{21}$ On the other hand, the refuge-seeking argument indicates that less talented doctorates get involved in a postdoctoral position and will be unlikely to fill future jobs in the academic area, implying a negative relationship between postdoctoral engagement and academic career. In this sense,

\footnotetext{
${ }^{21}$ We thank an anonymous referee for clarifying the link between our empirical results and the competing theories..
} 
the refuge-seeking jobs argument does not easily explain our empirical finding, which suggest that postdoctoral experience plays an important role in advancing to an academic career.

Our estimation about the effect of the postdoctoral engagement on the academic job choice is not only consistent with the aforementioned theoretical literature but is also in line with the prior empirical literature. Hanchane and Recotillet (2003) demonstrate that going through a postdoctoral program could increase the probability of being recruited as a researcher in the public sector by around 10\%. Nerad and Cerny (1999) report that "for mathematics postdocs, the time invested in a postdoc significantly improved the odds of gaining a faculty position." Our estimate (i.e., the marginal effect) is about $2.2 \%$ when the endogeneity problem is not taken into consideration (in Model 1 and Model 2 of Table 6). When we adopt the control function approach, those with postdoctoral experience will increase the probability more than twice (by about $6.1 \%$ ) of working in academically-oriented jobs with statistical significance (see Model 3 and Model 4 of Table 66.

Table 6 also indicates that the probability of obtaining an academic job is highly differentiated by fields of study. Those majoring in Science, Engineering, Agriculture and Health are more likely to work in non-academic institutions compared to Education majors, while holding a PhD in the Humanities, Social Sciences or Services does not lead to a significant tendency to choose academically-oriented jobs or not (see Models 3 and 4 in Table 6 that correct for the endogeneity problem). This may be because $\mathrm{PhD}$ graduates majoring in Science, Engineering, Agriculture or Health have more job opportunities in the private sector than in other fields of study. Our results are also along the lines of Neumann and Tan (2011), who report that "there are variations by disciplines" and the proportion of Science and Engineering graduates in academic careers is relatively small compared to that of those majoring in other disciplines.

\subsection{Heterogeneous Effects of Postdoctoral Experience}

As mentioned above, postdoctoral positions play an important role in choosing current jobs for doctorate holders using the entire sample. It turns out that gender, major, and birth cohort are essential to sorting PhD graduates into academic jobs. Due to our large sample size, we split the entire sample into several sub-samples by gender, major and birth cohort, respectively, to further investigate the heterogeneous effect of engaging in postdoctoral positions on the academic job choice for those sub-groups.

In terms of the effects of postdoctoral programs, Hanchane and Recotillet (2003) indicate that doctorate holders participating in a postdoctoral program increase the chances of their gaining academic jobs in the natural sciences, but does not improve the probability for those majoring in the human and social sciences in France. Our results in Table 7 show that those with postdoctoral experience majoring in Engineering would increase the probability of entering academic institutions (there is a significantly positive coefficient of postdoc in Table 7). However, those with postdoctoral experience majoring in Science would not have any statis- 
tically significant preference for academic jobs. It can be seen that even though postdoctoral experience encourages doctorates to enter academic-related positions, the impact of majoring in Science offsets the effect and leads to a vague outcome. This may be because getting involved in postdoctoral positions is a required probation period in Science (Nerad and Cerny, 1999; Stephan and Ma, 2005; Recotillet, 2007; NPA, 2011); thus, the advantage of postdoctoral experience in becoming a researcher is diminished for those majoring in Science. On the other hand, there may exist more job opportunities in private industry for those majoring in Engineering. If those majoring in Engineering choose a postdoctoral position after graduation, this may imply a strong preference for an academic career.

Recall the coefficient of gender in the case of using the entire sample in Table 6. It shows that males are more willing to join non-academic institutions than females. When we re-arrange the data by gender, the sub-sample estimation suggests that male doctoral degree holders with postdoctoral experience are more likely to choose academic positions than their female counterparts as shown in Table $8{ }^{22}$ Our finding for the gender differentiated effect is along the lines of the literature in Nerad and Cerny (1999), which summarizes a survey report to show that for those majoring in mathematics, "Ph.D.'s taking postdocs are more likely to obtain faculty positions, but this is true only for men." They also report that the ratio of mathematics postdocs employed as tenured faculty members in 1995 is $75 \%$ for males while the ratio is only $46 \%$ for females. Although a substantial percentage of women in mathematics holding postdoctoral appointments hope to become professors, most of them end up in business, government, or the non-profit sector rather than in academia (Nerad and Cerny, 1999). Our result is also consistent with NPA (2011), which mentions that "postdoc women, especially those that are married with children, are more likely than men to consider jobs outside academia."

We have found a significant effect of different cohorts on the choice of academic or nonacademic jobs in Table 6 based on the whole sample. The youngest cohort (born "after 1970") shows a significantly higher propensity for choosing non-academic positions than the oldest cohort. This is consistent with recent reports (Stephan, 2009; Fiegener, 2011; Neumann and Tan, 2011; Sauermann and Roach, 2012) that an increasing number of doctoral students have taken non-academic employment in recent decades; that is, academic jobs are no longer the primary choice for doctoral degree holders. The entire data set is split into three different cohorts ("before 1960", "between 1960 and 1969", and "after 1970") to consider the role of postdoctoral experience. It is observed that the postdoctoral experience for the older cohorts (born "before 1960" and "between 1960 and 1969") displays a significantly higher propensity for entering academic positions (see Table 9p. On the other hand, engaging in a postdoctoral position does not bring significant benefits for the youngest cohort (born "after 1970") in terms of finding a job in the academic sector. This may reflect that an academic job may not always be

\footnotetext{
${ }^{22}$ The separate regressions can be thought of as a more flexible or less restricted model than that based on the entire sample.
} 
the most attractive career choice in recent decades, that is, the social culture or value system has gradually changed to influence the higher education market. For instance, new PhDs may invest themselves or signal their ability by taking a postdoctoral position in order to enter a highly profitable industry. Based on the labor supply data in this paper, collecting the information on market demand ( $\mathrm{PhD}$ labor demand) over time shall enable us to better understand this phenomenon.

\section{Conclusions}

Postdoctoral positions are special transition positions that are only eligible for those with doctoral degrees. Postdoctoral participation could be regarded as investments to accumulate the additional human and social capital needed to facilitate future job search or to join an academic reserve army of unemployed PhDs. Given the prevalence of postdoctoral positions nowadays, it is crucial to explore the role played by postdoctoral participation in the post- $\mathrm{PhD}$ labor market.

This paper first reviews the underlying theories on whether engaging in a postdoctoral position is positively associated with advancing to an academic career. To empirically evaluate the benefits of engaging in a postdoctoral position, we take advantage of a comprehensive data set from NPHRST in Taiwan, which consists of a large number of doctorates with their postdoctoral status $(N=22,412)$, covers PhD holders across different disciplines and spans a long period of time ranging from 1920 to 1980 in terms of the birth cohorts. When inspecting the postdoctoral participation decision right after receiving a $\mathrm{PhD}$ degree, our findings reveal that older doctorates have a lower probability of taking up a postdoctoral position, and a longer elapsed time to the $\mathrm{PhD}$ degree is less likely to result in a postdoctoral position. The postdoctoral engagement also hinges on the field of study - those majoring in Science tend to engage in postdoctoral work more than those majoring in Social Science.

It is crucial to deal with the potential endogeneity issue when investigating the impact of postdoctoral experience on choosing academic jobs. We apply the control function approach to address this issue by first estimating the postdoctoral participation and then the career academic job choice. The empirical results suggest that engaging in postdoctoral positions has a positive effect in terms of finding a job in academia. More specifically, postdoctoral experience increases the probability of working in academically-oriented jobs by about $6.1 \%$. The human capital theory and education signaling theory are thereby indirectly supported by our empirical finding. We also observe the heterogeneous effects of gender, major and cohort in regard to the postdoctoral experience by splitting the data. Gaining postdoctoral experience does help males engineering majors and older cohorts obtain jobs in academia. In addition, we experiment with several groupings for the definition of being awarded an academic position and obtain very robust empirical results.

We acknowledge that family background may serve as one of the factors affecting $\mathrm{PhD}$ 
graduates' job choices, however, the current study is not able to take it into consideration due to the limitation of our data. We have urged the institution that collects the data to include such information and hopefully it can be utilized in our future research. In addition, most of the respondents in our sample are working in the academic institutions. There are about $76 \%$ male and nearly $40 \%$ doctoral holders major in Engineering. This unbalance proportion may generate the issue on unconstrained generalizability of our study. We will leave them to further studies.

\section{References}

[1] Åerlind, G. S. (2009). "Postdoctoral Research Positions as Preparation for an Academic Career," International Journal for Researcher Development, 1(1), 84-96.

[2] Bonnal, L. and J.-F. Giret (2008). "The Determinants of Delayed Entrance into the Academic Career: the Case of France," published in Labour Markets for Scientists and Engineers: International Workshop at Maastricht University, Maastricht: Netherlands.

[3] Cantwell, B. and B. J. Taylor (2013). "Internationalization of the Postdoctorate in the United States: Analyzing the Demand for International Postdoc Labor," High Education, 66:551-567.

[4] Cantwell, B. and J. J. Lee (2010). "Unseen Workers in the Academic Factory: Perceptions of Neoracism among International Postdocs in the US and UK," Harvard Educational Review, $80,490-516$.

[5] Collins, R. (1979). The Credential Society. New York: Academic Press.

[6] Commission on Professionals in Science and Technology (CPST) (2002). "Postdocs: What We Know and What We Would Like to Learn," Proceedings of an NSF/CPST Professional Societies Workshop, Washington, DC.

[7] Corley, E. A. and M. Sabharwal (2007). "Foreign-Born Academic Scientists and Engineers: Producing More and Getting Less than their U.S.-born Peers?" Research in Higher Education, 48(8), 909-940.

[8] Cyranoski, D., N. Gilbert, H. Ledford, A. Nayar and M. Yahia (2011). "The PhD Factory: the World is Producing more PhDs than ever before. Is it Time to Stop?" Nature, 472(7343), $276-279$.

[9] Fiegener, M. K. (2011). "Numbers of Doctorates Awarded in the United States Declined in 2010," NSF 12-303, NCSES (National Center for Science and Engineering Statistics). 
[10] Ghaffarzadegan, N., J. Hawley and A. Desai (2013). "Research Workforce Diversity: The Case of Balancing National versus International Postdocs in US Biomedical Research," Systems Research and Behavioral Science, DOI: 10.1002/sres.2190.

[11] Goldman, E. and E. Marshall (2002). "NIH Grantees: Where have all the Young Ones Gone?" Science, 298 (4), 40-41.

[12] Hanchane, S. and I. Recotillet (2003). "Academic Careers: The Effect of Participation to Post-doctoral Program," 15th SASE Conference, Aix-en-Provence, 26th-28th June.

[13] Hoffer, T. B., V. Jr. Welch, K. Webber, K. Williams, B. Lisek, M. Hess, D. Loew and I. Guzman-Barron (2006). "Doctorate Recipients from United States Universities: Summary Report 2005," Chicago: National Opinion Research Center.

[14] Horta, H. (2009). "Holding a Post-Doctoral Position before Becoming a Faculty Member: Does it Bring Benefits for the Scholarly Enterprise?" Higher Education, 58, 689-721.

[15] Igami, M., S. Nagaoka and J. P. Walsh (2014). "Contribution of Postdoctoral Fellows to Fast-moving and Competitive Scientific Research," Journal of Technology Transfer, DOI 10.1007/s10961-014-9366-7.

[16] Imbens, G. W. and J. M. Wooldridge (2007). "What's New in Econometrics?" NBER Lecture Notes 6, Summer 2007. http://www.nber.org/minicourse3.html.

[17] Jackson, D. and G. Michelson (2014). "Factors Influencing the Employment of Australian PhD Graduates," Studies in Higher Education, DOI:10.1080/03075079.2014.899344.

[18] Lan, X. (2012). "Permanent Visas and Temporary Jobs: Evidence from Postdoctoral Participation of Foreign PhDs in the United States," Journal of Policy Analysis and Management, $31(3), 623-640$.

[19] Lin, E. S. and S.-Y. Chiu (2014). "Can a Doctoral Degree be Completed Faster Overseas than Domestically? Evidence from Taiwanese Doctorates," Higher Education, 68, 263-283.

[20] McAlpine, L. and E. Emmioğlu (2014). "Navigating Careers: The Perceptions of Sciences Doctoral Students, Post-PhD Researchers, and Pre-tenure Academics," Studies in Higher Education, DOI: 10.1080/03075079.2014.914908.

[21] Mangematin, V. (2000). "PhD Job Market: Professional Trajectories and Incentives during the PhD," Research Policy, 29, 741-756.

[22] Musselin, C. (2004). "Towards a European Academic Labour Market? Some Lessons Drawn from Empirical Studies on Academic Mobility," Higher Education, 48, 55-78. 
[23] National Postdoctoral Association (NPA) (2011). "Postdoctoral Scholars, Gender, and the Academic Career Pipeline: A Fact Sheet." Developed as part of NPA ADVANCE, From Postdoc to Faculty: Transition Issues for Women Scientists Version March 2, 2011, Available from http://www . nationalpostdoc.org/component/rubberdoc/doc/299/raw.

[24] Nerad, M. and J. Cerny (1999). "Postdoctoral Patterns, Career Advancement, and Problems," Science, 285, 1533-1535.

[25] Neumann, R. and K. K. Tan (2011). "From PhD to Initial Employment: the Doctorate in a Knowledge Economy," Studies in Higher Education, 36(5), 601-614.

[26] Picciano, J., E. Rudd, E. Morrison and M. Nerad (2008). "Does Time-to-Degree Matter?" Technical Report, Spotlight on Doctoral Education, 3, CIRGE: University of Washington, Seattle, WA.

[27] Portnoi, L. (2009). "To be or not to be an Academic: South African Graduate Students' Vocational Choices," International Journal of Educational Development, 29, 406-414.

[28] Recotillet, I. (2007). "PhD Graduates With Post-Doctoral Qualification in the Private Sector: Does it Pay Off?" Labour, 21(3), 473-502.

[29] Robin, S. and E. Cahuzac (2003). "Knocking on Academia's Doors: An Inquiry into the Early Careers of Doctors in Life Sciences," Labour, 17(1), 1-23.

[30] Sauermann, H. and M. Roach (2012) "Science PhD Career Preferences: Levels, Changes, and Advisor Encouragement." PLoS ONE, 7(5): e36307. doi:10.1371/journal. pone.0036307.

[31] Schwabe, M. (2011). "The Career Paths of Doctoral Graduates in Austria," European Journal of Education, 46(1), Part II.

[32] Siegfried, J. J. and W. A. Stock (2001). "So You Want to Earn a PhD in Economics? How Long Do You Think It Will Take?" The Journal of Human Resources, 36(2), 364-378.

[33] Spence, A. (1973). “Job Market Signaling," Quarterly Journal of Economics, 87(2), 355374.

[34] Stephan, P. and J. Ma (2005). "The Increased Frequency and Duration of the Postdoctorate Career Stage," American Economic Review, 95(2): 71-75.

[35] Stephan, P. (2009). "Tracking the Placement of Students as a Measure of Technology Transfer," Advances in the Study of Entrepreneurship, Innovation and Economic Growth,19, 113140 .

[36] Stock, W. A., T. A. Finegan and J. J. Siegfried (2009). "Can You Earn a PhD in Economics in Five Years?" Economics of Education Review, 28, 523-537. 
[37] Su, X. (2013). "The Impacts of Postdoctoral Training on Scientists' Academic Employment," Journal of Higher Education, 84(2), 239-265.

[38] Townsend, R. B. (2012). "Who Are the New History PhDs?" NSF Snapshot from 2010 Provides Insights into Current Trends, American Historical Association, News column of the March 2012 issue of Perspectives on History.

[39] Zumeta, W. (1985). Extending the Educational Ladder: The Changing Roles of Postdoctoral Education in the United States. Springfield, VA: National Technical Information Service. 


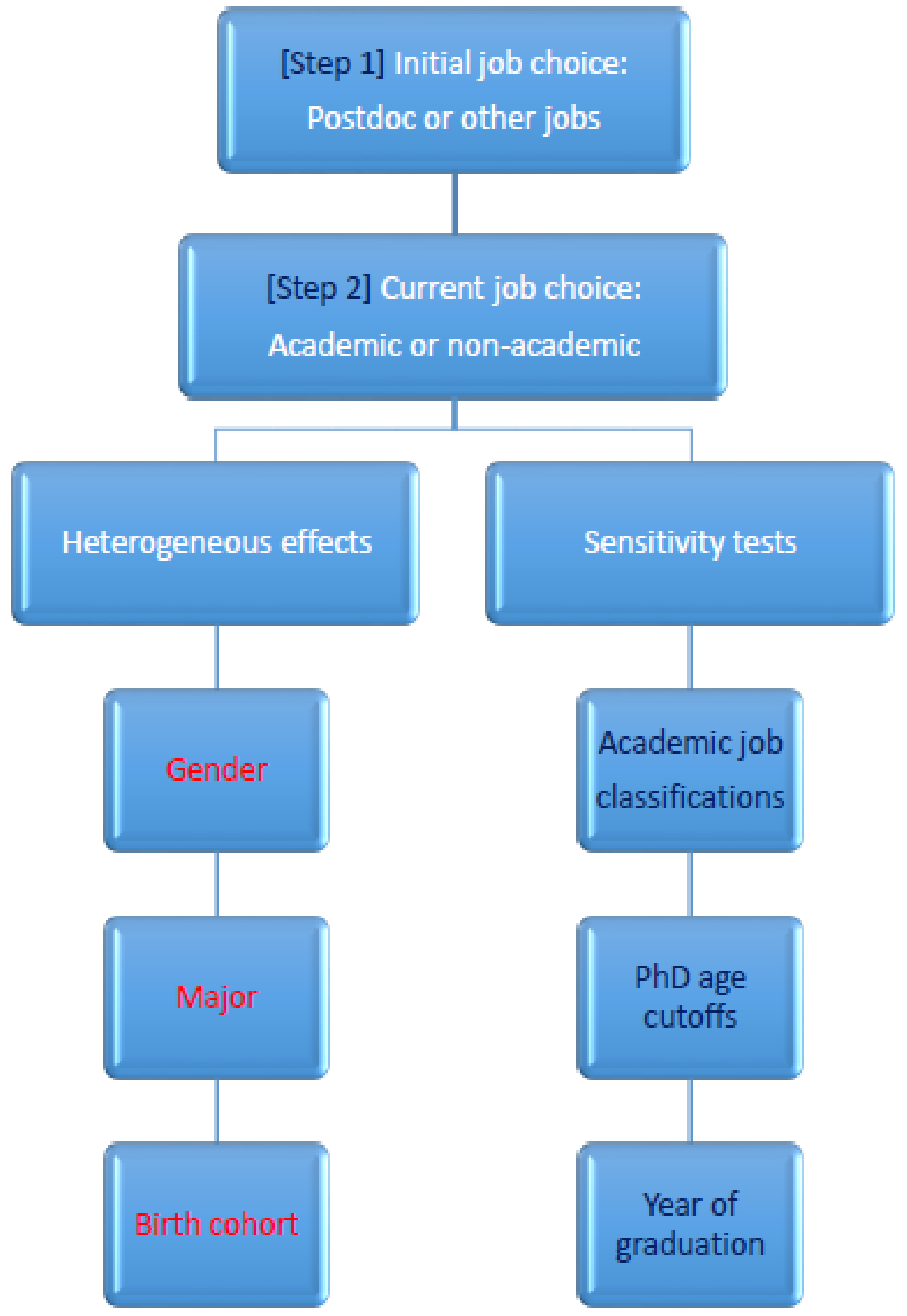

Figure 1: Empirical Structure of the Postdoctoral Effect on Academic Job Choice 
Table 1: Description of Variables

\begin{tabular}{|c|c|}
\hline Variables & Description of Variables \\
\hline ETTD & the elapsed time to the doctoral degree \\
\hline Age & age obtaining the doctoral degree \\
\hline Gap & search time to the first job after receiving doctoral degree \\
\hline Gender $^{a}$ & male $=1$ and female $=0$ \\
\hline \multicolumn{2}{|l|}{ School Types } \\
\hline Domestic & domestic universities/colleges \\
\hline Public & domestic public universities/colleges \\
\hline Private & domestic private universities/colleges \\
\hline Foreign & foreign universities/colleges \\
\hline \multicolumn{2}{|l|}{ Majors } \\
\hline Education & major in education \\
\hline Humanities & major in humanities and the arts \\
\hline SocialScience & major in social science, business and law \\
\hline Science & major in science \\
\hline Engineering & major in engineering, manufacturing and construction \\
\hline Agriculture & major in agriculture \\
\hline Health & major in health and welfare \\
\hline Services & major in services \\
\hline \multicolumn{2}{|l|}{ Cohorts } \\
\hline Born1960 & those born before 1960 \\
\hline Born60-69 & those born between 1960 and 1969 \\
\hline Born1970 & those born after 1970 \\
\hline \multicolumn{2}{|l|}{ Tier } \\
\hline Top30 & top 30 schools are filtered based on 2010 Academic Ranking of World Universities \\
\hline Top31-100 & $\begin{array}{l}\text { school rankings between top } 31 \text { and top } 100 \text { are filtered based on } 2010 \text { Academic } \\
\text { Ranking of World Universities }\end{array}$ \\
\hline \multicolumn{2}{|r|}{ (2) } \\
\hline Postdoc & $\begin{array}{l}\text { those who choose to do the postdoctoral job after graduation rather than other } \\
\text { full-time jobs }\end{array}$ \\
\hline \multicolumn{2}{|c|}{ Interaction Term } \\
\hline Edu-Foreign & interaction term of foreign universities/colleges and major in Education \\
\hline Hum-Foreign & interaction term of foreign universities/colleges and major in Humanities \\
\hline Soc-Foreign & interaction term of foreign universities/colleges and major in SocialScience \\
\hline Sci-Foreign & interaction term of foreign universities/colleges and major in Science \\
\hline Eng-Foreign & interaction term of foreign universities/colleges and major in Engineering \\
\hline Agr-Foreign & interaction term of foreign universities/colleges and major in Agriculture \\
\hline Med-Foreign & interaction term of foreign universities/colleges and major in Health \\
\hline Ser-Foreign & interaction term of foreign universities/colleges and major in Services \\
\hline \multicolumn{2}{|c|}{ Graduation Season } \\
\hline Sea-First & Graduation in the first season (Jan. - Mar.) \\
\hline Sea-Second & Graduation in the second season (Apr. - June) \\
\hline Sea-Third & Graduation in the third season (July - Sept.) \\
\hline Sea-Fourth & Graduation in the fourth season (Oct. - Dec.) \\
\hline
\end{tabular}

Note: According to "a", the variables following are dummies by nature. 
Table 2: Summary Statistics of Total Sample and by Cohort

Total Sample

\begin{tabular}{lrrrr}
\hline & Mean & Std & Min & Max \\
\hline ETTD & 4.76 & 1.4650 & 2.1 & 10.0 \\
Age & 33.85 & 4.6978 & 22.0 & 59.0 \\
Gap & 0.62 & 0.7171 & 0.1 & 3.3 \\
Obs. & \multicolumn{4}{c}{22,412} \\
\hline \multicolumn{5}{c}{} \\
Cohort Born Before 1960 \\
\hline \multicolumn{5}{c}{ Mean } \\
ETtd & Min & Max \\
Age & 4.68 & 1.5069 & 2.1 & 10.0 \\
Gap & 36.38 & 5.5454 & 25.0 & 59.0 \\
Obs. & 0.65 & 0.7640 & 0.1 & 3.3 \\
\hline
\end{tabular}

Cohort Born Between 1960 and 1969

\begin{tabular}{lrrrr}
\hline & Mean & Std & Min & Max \\
\hline ETTD & 4.84 & 1.5097 & 2.1 & 10.0 \\
Age & 33.85 & 4.0136 & 22.0 & 49.0 \\
Gap & 0.64 & 0.7338 & 0.1 & 3.3 \\
Obs. & \multicolumn{4}{c}{10,691} \\
\hline
\end{tabular}

Cohort Born After 1970

\begin{tabular}{lrrrr}
\hline & Mean & Std & Min & Max \\
\hline ETTD & 4.68 & 1.3040 & 2.1 & 10.0 \\
Age & 30.77 & 2.5094 & 24.0 & 40.0 \\
Gap & 0.55 & 0.6120 & 0.1 & 3.3 \\
Obs. & \multicolumn{4}{c}{5,289} \\
\hline
\end{tabular}


Table 3: Percentages based on First Job Choices after Receiving PhD degree

\begin{tabular}{|c|c|c|c|}
\hline & Postdoc (\%) & Full-job (\%) & Total $(\%)$ \\
\hline \multicolumn{4}{|l|}{ Gender } \\
\hline Female & 14.09 & 85.91 & 23.25 \\
\hline Male & 15.13 & 84.87 & 76.75 \\
\hline \multicolumn{4}{|l|}{ School Types } \\
\hline Domestic & 14.29 & 85.71 & 54.04 \\
\hline Foreign & 15.59 & 84.41 & 45.96 \\
\hline \multicolumn{4}{|l|}{ Majors } \\
\hline Education & 2.46 & 97.54 & 5.97 \\
\hline Humanities & 5.37 & 94.63 & 7.31 \\
\hline SocialScience & 3.62 & 96.38 & 17.37 \\
\hline Science & 39.51 & 60.49 & 16.65 \\
\hline Engineering & 11.08 & 88.92 & 39.34 \\
\hline Agriculture & 23.76 & 76.24 & 4.86 \\
\hline Health & 21.61 & 78.39 & 7.21 \\
\hline Services & 5.52 & 94.48 & 1.29 \\
\hline \multicolumn{4}{|l|}{ Cohorts } \\
\hline Born1960 & 8.69 & 91.31 & 28.70 \\
\hline Born60-69 & 15.23 & 84.77 & 47.70 \\
\hline Born1970 & 21.74 & 78.26 & 23.60 \\
\hline \multicolumn{4}{|l|}{ Tier } \\
\hline Top30 & 19.62 & 80.38 & 9.03 \\
\hline Top31-100 & 16.92 & 83.08 & 10.31 \\
\hline \multicolumn{4}{|c|}{ Graduation Season } \\
\hline Sea-First & 14.94 & 85.06 & 15.21 \\
\hline Sea-Second & 13.87 & 86.13 & 49.93 \\
\hline Sea-Third & 15.74 & 84.26 & 20.69 \\
\hline Sea-Fourth & 17.19 & 82.81 & 14.17 \\
\hline Total (\%) & 14.89 & 85.11 & 100.00 \\
\hline
\end{tabular}


Table 4: Sample Size based on Academic vs. Non-Academic Job Choices

\begin{tabular}{|c|c|c|c|}
\hline & Non-Academic & Academic & Total \\
\hline \multicolumn{4}{|l|}{ Gender } \\
\hline Female & 88 & 5,123 & 5,211 \\
\hline Male & 1,233 & 15,968 & 17,201 \\
\hline \multicolumn{4}{|l|}{ School Types } \\
\hline Public & 959 & 9,879 & 10,838 \\
\hline Private & 78 & 1,196 & 1,274 \\
\hline Foreign & 284 & 10,016 & 10,300 \\
\hline \multicolumn{4}{|l|}{ Majors } \\
\hline Education & 11 & 1,328 & 1,339 \\
\hline Humanities & 8 & 1,631 & 1,639 \\
\hline SocialScience & 56 & 3,836 & 3,892 \\
\hline Science & 234 & 3,497 & 3,731 \\
\hline Engineering & 853 & 7,963 & 8,816 \\
\hline Agriculture & 34 & 1,056 & 1,090 \\
\hline Health & 119 & 1,496 & 1,615 \\
\hline Services & 6 & 284 & 290 \\
\hline \multicolumn{4}{|l|}{ Cohorts } \\
\hline Born1960 & 233 & 6,199 & 6,432 \\
\hline Born60-69 & 430 & 10,261 & 10,691 \\
\hline Born1970 & 658 & 4,631 & 5,289 \\
\hline \multicolumn{4}{|l|}{ Tier } \\
\hline Top30 & 60 & 1,963 & 2,023 \\
\hline Top31-100 & 60 & 2,251 & 2,311 \\
\hline \multicolumn{4}{|c|}{ Working Experience } \\
\hline Postdoc & 154 & 3,183 & 3,337 \\
\hline Total & 1,321 & 21,091 & 22,412 \\
\hline
\end{tabular}


Table 5: Binary Probit Estimates of the First Job Choices

\begin{tabular}{|c|c|c|c|c|c|c|c|c|}
\hline & \multicolumn{2}{|c|}{ Model 1} & \multicolumn{2}{|c|}{ Model 2} & \multicolumn{2}{|c|}{ Model 3} & \multicolumn{2}{|c|}{ Model 4} \\
\hline & Coefficient & Mar. & Coefficient & Mar. & Coefficient & Mar. & Coefficient & Mar. \\
\hline ETTD & $0.0886^{*}$ & 0.0150 & $0.0877^{*}$ & 0.0148 & $0.0878^{*}$ & 0.0149 & $0.0871^{*}$ & 0.0147 \\
\hline Age & $-0.0632^{*}$ & -0.0107 & $-0.0624^{*}$ & -0.0105 & $-0.0631^{*}$ & -0.0107 & $-0.0623^{*}$ & -0.0105 \\
\hline Gap & $-0.3617^{*}$ & -0.0614 & $-0.3603^{*}$ & -0.0609 & $-0.3623^{*}$ & -0.0614 & $-0.3604^{*}$ & -0.0608 \\
\hline Male & $0.0861^{*}$ & 0.0142 & $0.0841^{*}$ & 0.0138 & $0.0847^{*}$ & 0.0139 & $0.0829^{*}$ & 0.0136 \\
\hline \multicolumn{9}{|l|}{ School Types } \\
\hline Public & & & $0.3426^{*}$ & 0.0585 & & & $0.3564^{*}$ & 0.0608 \\
\hline Foreign & $0.1224^{*}$ & 0.0209 & $0.4353^{*}$ & 0.0756 & -0.0937 & -0.0158 & 0.2636 & 0.0452 \\
\hline \multicolumn{9}{|l|}{ Majors } \\
\hline Humanities & $0.3395^{*}$ & 0.0690 & $0.3708^{*}$ & 0.0763 & 0.0810 & 0.0143 & 0.1611 & 0.0297 \\
\hline SocialScience & 0.0781 & 0.0137 & 0.0898 & 0.0158 & -0.0616 & -0.0102 & -0.0274 & -0.0046 \\
\hline Science & $1.5921^{*}$ & 0.4498 & $1.6005^{*}$ & 0.4519 & $1.4262^{*}$ & 0.3912 & $1.4525^{*}$ & 0.3995 \\
\hline Engineering & $0.5620^{*}$ & 0.1036 & $0.5645^{*}$ & 0.1038 & $0.4284^{*}$ & 0.0773 & $0.4462^{*}$ & 0.0804 \\
\hline Agriculture & $1.2816^{*}$ & 0.3794 & $1.2765^{*}$ & 0.3767 & $1.1645^{*}$ & 0.3343 & $1.1698^{*}$ & 0.3356 \\
\hline Health & $1.1716^{*}$ & 0.3308 & $1.2170^{*}$ & 0.3470 & $1.0678^{*}$ & 0.2923 & $1.1765^{*}$ & 0.3316 \\
\hline Services & $0.2704^{\dagger}$ & 0.0541 & $0.2697^{\dagger}$ & 0.0537 & 0.1464 & 0.0272 & 0.1474 & 0.0273 \\
\hline \multicolumn{9}{|l|}{ Cohorts } \\
\hline Born60-69 & $0.3878^{*}$ & 0.0668 & $0.3847^{*}$ & 0.0660 & $0.3891^{*}$ & 0.0670 & $0.3871^{*}$ & 0.0663 \\
\hline Born1970 & $0.5716^{*}$ & 0.1173 & $0.5725^{*}$ & 0.1171 & $0.571^{*}$ & 0.1170 & $0.5741^{*}$ & 0.1173 \\
\hline \multicolumn{9}{|l|}{ Tier } \\
\hline Top30 & $0.1186^{*}$ & 0.0214 & $0.1194^{*}$ & 0.0215 & $0.1189^{*}$ & 0.0214 & $0.1192^{*}$ & 0.0214 \\
\hline Top31-100 & $0.0705^{\dagger}$ & 0.0124 & $0.0711^{\dagger}$ & 0.0125 & $0.0708^{\dagger}$ & 0.0124 & $0.0710^{\dagger}$ & 0.0124 \\
\hline \multicolumn{9}{|c|}{ Graduation Season } \\
\hline Sea-First & -0.0024 & -0.0004 & 0.0008 & 0.0001 & -0.0044 & -0.0008 & -0.0002 & 0.0000 \\
\hline Sea-Second & $-0.1633^{*}$ & -0.0277 & $-0.1581^{*}$ & -0.0267 & $-0.1629^{*}$ & -0.0276 & $-0.1575^{*}$ & -0.0266 \\
\hline Sea-Third & $-0.0751^{\dagger}$ & -0.0124 & $-0.0746^{\dagger}$ & -0.0122 & $-0.076^{\dagger}$ & -0.0125 & $-0.0751^{\dagger}$ & -0.0123 \\
\hline \multicolumn{9}{|c|}{ Interaction Term } \\
\hline Hum-Foreign & & & & & $0.4205^{\dagger}$ & 0.0904 & $0.3406^{\dagger}$ & 0.0699 \\
\hline Soc-Foreign & & & & & 0.2132 & 0.0405 & 0.18 & 0.0334 \\
\hline Sci-Foreign & & & & & 0.2615 & 0.0507 & 0.2371 & 0.0453 \\
\hline Eng-Foreign & & & & & 0.1966 & 0.0364 & 0.1811 & 0.0332 \\
\hline Agr-Foreign & & & & & 0.1558 & 0.0290 & 0.1516 & 0.0281 \\
\hline Med-Foreign & & & & & 0.1412 & 0.0260 & 0.0329 & 0.0057 \\
\hline Ser-Foreign & & & & & 0.1887 & 0.0360 & 0.1883 & 0.0357 \\
\hline Constant & $-0.4039^{*}$ & & $-0.7485^{*}$ & & -0.2615 & & $-0.6428^{*}$ & \\
\hline Obs. & \multicolumn{2}{|c|}{22,412} & \multicolumn{2}{|c|}{22,412} & \multicolumn{2}{|c|}{22,412} & \multicolumn{2}{|c|}{22,412} \\
\hline
\end{tabular}

Notes: ${ }^{\dagger},{ }^{\dagger}$, and $*$ denote statistical significance at the $10 \%, 5 \%$, and $1 \%$ levels, respectively. 
Table 6: Binary Probit Estimates of Academic or Non-academic Positions

\begin{tabular}{|c|c|c|c|c|c|c|c|c|}
\hline & \multicolumn{4}{|c|}{ w/o Considering Endogeneity Problem } & \multicolumn{4}{|c|}{ Considering Endogeneity Problem } \\
\hline & \multicolumn{2}{|c|}{ Model 1} & \multicolumn{2}{|c|}{ Model 2} & \multicolumn{2}{|c|}{ Model 3} & \multicolumn{2}{|c|}{ Model 4} \\
\hline & Coefficient & Mar. & Coefficient & Mar. & Coefficient & Mar. & Coefficient & Mar. \\
\hline Postdoc & $0.3690^{*}$ & 0.0223 & $0.3722^{*}$ & 0.0225 & $1.8854^{*}$ & 0.0610 & $1.9118^{*}$ & 0.0615 \\
\hline ETTD & $-0.0395^{*}$ & -0.0030 & $-0.0386^{*}$ & -0.0029 & $-0.0559^{*}$ & -0.0042 & $-0.0549^{*}$ & -0.0041 \\
\hline Age & $0.0382^{*}$ & 0.0029 & $0.0378^{*}$ & 0.0029 & $0.0493^{*}$ & 0.0037 & $0.0487^{*}$ & 0.0037 \\
\hline Male & $-0.4746^{*}$ & -0.0292 & $-0.4740^{*}$ & -0.0291 & $-0.4868^{*}$ & -0.0295 & $-0.4859^{*}$ & -0.0295 \\
\hline \multicolumn{9}{|l|}{ School Types } \\
\hline Public & & & $-0.1144^{\dagger}$ & -0.0087 & & & $-0.2033^{*}$ & -0.0155 \\
\hline Foreign & $0.3609^{*}$ & 0.0271 & $0.2582^{*}$ & 0.0194 & $0.3285^{*}$ & 0.0245 & $0.1463^{\dagger}$ & 0.0109 \\
\hline \multicolumn{9}{|l|}{ Majors } \\
\hline Humanities & $0.3119^{\dagger}$ & 0.0187 & 0.2896 & 0.0176 & 0.2935 & 0.0177 & 0.2579 & 0.0159 \\
\hline SocialScience & -0.0110 & -0.0008 & -0.0203 & -0.0016 & 0.0016 & 0.0001 & -0.0123 & -0.0009 \\
\hline Science & $-0.6873^{*}$ & -0.0796 & $-0.6955^{*}$ & -0.0809 & $-1.1950^{*}$ & -0.1822 & $-1.2145^{*}$ & -0.1869 \\
\hline Engineering & $-0.6987^{*}$ & -0.0632 & $-0.7032^{*}$ & -0.0637 & $-0.7767^{*}$ & -0.0714 & $-0.7844^{*}$ & -0.0722 \\
\hline Agriculture & $-0.3651^{\dagger}$ & -0.0373 & $-0.3657^{\dagger}$ & -0.0374 & $-0.6671^{*}$ & -0.0854 & $-0.6714^{*}$ & -0.0862 \\
\hline Health & $-0.9199^{*}$ & -0.1372 & $-0.9441^{*}$ & -0.1429 & $-1.1847^{*}$ & -0.2061 & $-1.2286^{*}$ & -0.2189 \\
\hline Services & -0.1933 & -0.0174 & -0.1932 & -0.0174 & -0.2123 & -0.0193 & -0.2121 & -0.0193 \\
\hline \multicolumn{9}{|l|}{ Cohorts } \\
\hline Born60-69 & $0.1248^{*}$ & 0.0095 & $0.1254^{*}$ & 0.0095 & 0.0338 & 0.0026 & 0.0341 & 0.0026 \\
\hline Born1970 & $-0.3008^{*}$ & -0.0266 & $-0.3026^{*}$ & -0.0267 & $-0.4778^{*}$ & -0.0459 & $-0.4822^{*}$ & -0.0464 \\
\hline \multicolumn{9}{|l|}{ Tier } \\
\hline Top30 & 0.0658 & 0.0048 & 0.0651 & 0.0047 & 0.0205 & 0.0015 & 0.0187 & 0.0014 \\
\hline Top31-100 & 0.0619 & 0.0045 & 0.0612 & 0.0044 & 0.0387 & 0.0028 & 0.0372 & 0.0027 \\
\hline$\hat{u}$ & & & & & $-1.5421^{*}$ & -0.1165 & $-1.5655^{*}$ & -0.1182 \\
\hline Constant & $1.3114^{*}$ & & $1.4328^{*}$ & & $1.0590^{*}$ & & $1.2669^{*}$ & \\
\hline Obs. & 22,4 & & 22,4 & & 22,4 & & 22 , & \\
\hline
\end{tabular}

Note: ${ }^{\dagger},{ }^{\dagger}$, and ${ }^{*}$ denote statistical significance at the $10 \%, 5 \%$, and $1 \%$ levels, respectively. 
Table 7: Binary Probit Estimates of Academic or Non-academic Positions by Major

\begin{tabular}{lcrrrrr}
\hline & \multicolumn{2}{c}{ Science } & \multicolumn{2}{c}{ Engineering } & \multicolumn{2}{c}{ Other Majors } \\
\hline & Coefficient & Mar. & Coefficient & Mar. & Coefficient & Mar. \\
\hline Postdoc & 0.1454 & 0.0149 & $2.2725^{*}$ & 0.1040 & $5.0024^{*}$ & 0.0550 \\
ETTD & -0.0180 & -0.0019 & $-0.0818^{*}$ & -0.0104 & 0.0007 & 0.0000 \\
Age & 0.0171 & 0.0018 & $0.0820^{*}$ & 0.0105 & $0.0374^{*}$ & 0.0018 \\
Male & $-0.3075^{*}$ & -0.0280 & $-0.7037^{*}$ & -0.0560 & $-0.4307^{*}$ & -0.0198 \\
School Types & & & & & & \\
Foreign & $0.3352^{*}$ & 0.0364 & $0.5056^{*}$ & 0.0597 & 0.1050 & 0.0052 \\
Cohorts & & & & & & \\
Born60-69 & 0.1675 & 0.0174 & -0.0756 & -0.0097 & 0.0717 & 0.0035 \\
Born1970 & $-0.2572^{\dagger}$ & -0.0304 & $-0.7531^{*}$ & -0.1249 & -0.0668 & -0.0034 \\
Tier & & & & & & \\
Top30 & 0.1668 & 0.0158 & -0.1167 & -0.0160 & $-0.1891^{\dagger}$ & -0.0109 \\
Top31-100 & 0.1482 & 0.0142 & -0.0764 & -0.0102 & 0.0238 & 0.0011 \\
h & 0.1868 & 0.0196 & $-1.8793^{*}$ & -0.2399 & $-5.0754^{*}$ & -0.2491 \\
Constant & $1.1045^{\dagger}$ & & -0.3370 & & 0.4819 & \\
\hline Obs. & 3,731 & 8,816 & & 9,865 \\
\hline
\end{tabular}

Notes: ${ }^{\dagger},{ }^{\dagger}$, and $*$ denote statistical significance at the $10 \%, 5 \%$, and $1 \%$ levels, respectively. 
Table 8: Binary Probit Estimates of Academic or Non-academic Positions by Gender

\begin{tabular}{lcrcr}
\hline \multicolumn{3}{c}{ Female } & \multicolumn{2}{c}{ Male } \\
\hline & Coefficient & Mar. & Coefficient & Mar. \\
\hline Postdoc & 1.4353 & 0.0171 & $1.8390^{*}$ & 0.0808 \\
ETTD & $-0.0989^{\dagger}$ & -0.0027 & $-0.0454^{*}$ & -0.0045 \\
Age & 0.0240 & 0.0007 & $0.0512^{*}$ & 0.0050 \\
School Types & & & & \\
Foreign & 0.0966 & 0.0026 & $0.3441^{*}$ & 0.0329 \\
Majors & & & & \\
Humanities & 0.3310 & 0.0071 & 0.2319 & 0.0191 \\
SocialScience & 0.1185 & 0.0030 & -0.1279 & -0.0135 \\
Science & $-1.0574^{\dagger}$ & -0.0710 & $-1.2723^{*}$ & -0.2386 \\
Engineering & -0.6071 & -0.0296 & $-0.8915^{*}$ & -0.0949 \\
Agriculture & -0.8034 & -0.0503 & $-0.6841^{*}$ & -0.1095 \\
Health & $-0.8161^{\dagger}$ & -0.0456 & $-1.4021^{*}$ & -0.3247 \\
Services & - & - & -0.4048 & -0.0547 \\
Cohorts & & & & \\
Born60-69 & $0.4292^{*}$ & 0.0124 & -0.0201 & -0.0020 \\
Born1970 & 0.2510 & 0.0060 & $-0.5855^{*}$ & -0.0754 \\
Tier & & & & \\
Top30 & 0.2443 & 0.0053 & -0.0059 & -0.0006 \\
Top31-100 & 0.2851 & 0.0061 & -0.0017 & -0.0002 \\
$\hat{u}$ & -1.4745 & -0.0401 & $-1.4343^{*}$ & -0.1410 \\
Constant & $1.6723^{\dagger}$ & & $0.6434^{\dagger}$ & \\
\hline Obs. & \multicolumn{3}{c}{5,152} & \multicolumn{2}{c}{17,201} \\
\hline
\end{tabular}

Note: ${ }^{\dagger},{ }^{\dagger}$, and $*$ denote statistical significance at the $10 \%, 5 \%$, and $1 \%$ levels, respectively. 
Table 9: Binary Probit Estimates of Academic or Non-academic Positions by Cohorts

\begin{tabular}{lcrrrrr}
\hline & \multicolumn{2}{c}{ Born Before 1960} & \multicolumn{2}{c}{ Born Between 60-69 } & \multicolumn{2}{c}{ Born After 1970} \\
\hline & Coefficient & Mar. & Coefficient & Mar. & Coefficient & Mar. \\
\hline Postdoc & $2.9829^{*}$ & 0.0519 & $2.0417^{*}$ & 0.0497 & 0.1189 & 0.0129 \\
ETTD & -0.0315 & -0.0021 & $-0.0641^{*}$ & -0.0038 & $-0.0952^{*}$ & -0.0109 \\
Age & $0.0198^{\dagger}$ & 0.0013 & $0.0574^{*}$ & 0.0034 & $0.1210^{*}$ & 0.0138 \\
Male & -0.0966 & -0.0061 & $-0.4877^{*}$ & -0.0233 & $-0.641^{*}$ & -0.0581 \\
School Types & & & & & & \\
Foreign & -0.0188 & -0.0013 & $0.3081^{*}$ & 0.0178 & $0.5418^{*}$ & 0.0500 \\
Majors & & & & & & \\
Humanities & 0.2060 & 0.0118 & 0.1101 & 0.0059 & 0.5538 & 0.0429 \\
SocialScience & -0.1727 & -0.0130 & -0.2402 & -0.0165 & 0.3726 & 0.0352 \\
Science & $-1.2190^{*}$ & -0.1684 & $-1.4196^{\dagger}$ & -0.2074 & -0.5620 & -0.0866 \\
Engineering & $-0.4221^{\dagger}$ & -0.0324 & -0.8347 & -0.0628 & -0.8030 & -0.1006 \\
Agriculture & $-0.5487^{\dagger}$ & -0.0578 & -0.8037 & -0.0936 & -0.3036 & -0.0431 \\
Health & $-1.3226^{*}$ & -0.2299 & $-1.4153^{\dagger}$ & -0.2400 & -0.2228 & -0.0296 \\
Services & $-0.5621^{\dagger}$ & -0.0624 & 0.0470 & 0.0026 & -0.0205 & -0.0024 \\
Tier & & & & & & \\
Top30 & -0.0222 & -0.0015 & -0.0938 & -0.0059 & $0.6893^{\dagger}$ & 0.0479 \\
Top31-100 & 0.0708 & 0.0046 & -0.1090 & -0.0070 & 0.2872 & 0.0267 \\
$\hat{u}$ & $-2.9768^{*}$ & -0.2006 & $-1.8554^{*}$ & -0.1090 & 0.4907 & 0.0560 \\
Constant & $1.6664^{*}$ & & 0.9803 & & -1.0341 & \\
\hline Obs. & 6,432 & \multicolumn{7}{c}{10,691} & & 5,289 & \\
\hline & \multicolumn{7}{c}{} & & & & & \\
\hline
\end{tabular}

Note: ${ }^{\dagger},{ }^{\dagger}$, and $*$ denote statistical significance at the $10 \%, 5 \%$, and $1 \%$ levels, respectively. 